\title{
Effect of Nursing Intervention Program on Quality of Life Improvement for Women Undergoing Gynecological and Breast Cancer Treatment
}

\author{
Fatma, S. Nady ${ }^{1}$, Mamdouh E said ${ }^{2}$, Entisar, M. Youness ${ }^{3}$ \& Hanan, E. Hassan ${ }^{4}$. \\ Assistant lecturer in Maternal \& Newborn Health Nursing, Faculty of Nursing, Beni-Suief University. \\ Professor of oncology, Faculty of Medicine, Beni-Suief University. \\ Assistant Professor of Obstetrics and Gynecological Nursing, Faculty of Nursing, Assuit University. \\ Lecturer of Maternal \& Newborn Health Nursing, Faculty of Nursing, Beni-Suief University.
}

\begin{abstract}
Background: Breast and gynecological cancer are the most common type of cancer in women and need rehabilitation programs to improve QOL. Aim of the study was to assess the effectiveness of nursing intervention program on QOL improvement in women undergoing treatment for gynecological and breast cancer. Study design: A quasi experimental study design. Sample and settings: A randomly selected sample of 100 women diagnosed with gynecological and breast cancer who attended the oncology institute, and divided to two groups, the study group and control group. Tool structured interview questionnaire included socio-personal data, oncology treatment side effects record, reproductive concerns scale, female sexual function index, impact of event scale" cancer specific stress", and functional assessment of cancer therapy-general. Results: Quality of life of the intervention group with breast and gynecological cancer have been improved under the influence of the nursing intervention program. Conclusion and Recommendations: The nursing intervention program showed evidence of improved QOL, with a reduction in the sexual dysfunction, and lower stress levels. It was suggested to heighten awareness about the breast and gynecological cancer treatment-related side effects among the nursing staff.
\end{abstract}

\section{Key words: Nursing Intervention, Gynecological Cancer, Reproductive Concerns-Sexual Dysfunction \& Quality of Life "QOL".}

\section{Introduction}

Gynecological cancer refers to cancers involving the female reproductive tract, i.e. cervix, uterus, ovary, vulva, vagina and fallopian tubes (National Cancer Institute [NCI], 2010) Despite the recent, slight decline in prevalence rates, new female cancer cases continue to be overwhelming. The American Cancer Association (ACS) issued a 2009 report stating that annually, American women most frequently develop the following cancers (listed in descending order): new cases of breast cancer) 192,370), lung cancer (103,350), colon cancer $(71,380$, (uterine cancer $(42,160)$, lymphoma $(33,860)$, skin cancer $(31,690)$, ovarian cancer $(21,550)$, and cervical cancer $(11,270)$ (American Cancer Society [ACS], 2012).

Breast cancer is the most commonly occurring form of cancer in women. In 2014, approximately 19,105 new cases were diagnosed in Egypt, and 2,395 new cases for ovarian cancer 2014 (Ibrahim et al., 2014). The breast and ovarian mortality rate was $21.6 \%$ and $5.0 \%$ respectively (World Health Organization, 2014) About $25 \%$ of breast and gynecologic cancers are diagnosed in women under the age of 50 (ACS, 2013).

As the overall death rate for women with cancer declines, the number of survivors continues to grow. Recently, the NCI of Cancer Survivorship (2010) reported that there are 7.2 million female cancer survivors today, which include $68 \%$ surviving at least an average of five years after diagnosis. Subsequently, unprecedented survivorship issues concerning psychosocial needs for women have become the new focus for healthcare providers and researchers

While specific treatment recommendations will depend on cancer site, stage, and tumor characteristics, women with breast or gynecologic cancer will typically be treated with surgery followed by adjuvant chemotherapy, radiation, and/or hormonal therapies. Quality of life is a broad multidimensional concept that considers a person's physical, emotional, social, and spiritual well-being (Weaver et al.,2012).

For many patients with cancer, the goal of therapy is as much improved QOL as it is eliminating the tumor cells. While QOL varies markedly among cancer types, a considerable proportion of all patients experience negative effects of cancer and its treatments resulting in decreased QOL. Individuals who have a history of more invasive and aggressive treatments tend to report poorer functioning and QOL in the long term (Kent et al., 2015) Due to the nature of the disease and treatment modalities typically utilized, many cancer survivors report psychosocial and Health related quality of life (HRQOL) effects (Bloom, 2008) Merely staying alive is no longer considered the target in medical interventions and people have come to demand a better quality of life 
as well. Clinical health care providers can help with the control and treatment of diseases and consequently the improvement of the quality of life health care providers may need to pay special attention to women undergoing treatment for breast cancer and perform timely measures to maintain their belief in themselves (Fahimeh et al., 2018).

Nurses, as one of the members of treatment team, have an important role in diagnosis, treatment, and caring patients with cancer and as they spend more time with the patient compared to the other treatment team members, they may be the first people who can recognize the needs of patients and their families and be effective in controlling disease complications and treatment as well as enhancing QOL of the patients (Milne et al., 2008).

\section{Significance of the study}

Breast cancer is the most commonly occurring form of cancer in women. In 2014, approximately 19,105 new cases were diagnosed in Egypt, and 2,395 new cases for ovarian cancer (Ibrahim et al., 2014). The breast and ovarian mortality rate was $21.6 \%$ and $5.0 \%$ respectively (World Health Organization [WHO], 2014). About $25 \%$ of breast and gynecological cancer are diagnosed in women under the age of 50 years (ACS, 2013). Diagnosis and treatment of cancer are stressful events and result in various physical, psychological, behavioral, social, and spiritual concerns, which are often experienced after treatment (Liao et al.,2014).

Assessing and improving QOL status in cancer women is important for several reasons, particularly because it provides supplementary information about the impact of the disease and its treatment on cancer women to aid health care providers in selecting both antineoplastic and supportive-care therapy. Given the chronic and often incurable nature of many gynecologic malignancies, the toxicity and tolerability of a specific therapy that might be as important as its efficacy, as is the ability to help ameliorate or prevent many of the associated toxicities that negatively affect QOL.

The usual care given during cancer treatment tends to focus on procedures, side effects of treatment, and its process rather than on the resulting symptoms and their management .Therefore, a more comprehensive approach to help women with their symptom management is required.

\section{Aim of the study}

To assess the effectiveness of nursing intervention program on QoL improvement in women undergoing treatment for gynecological and breast cancer.

\section{Research Hypothesis}

Quality of life of women with gynecological and breast cancer who receives nursing intervention program will be improved than those who won't.

\section{Subjects \& Methods \\ Research design}

A quasi experimental research design was adopted.

Settings

The study was conducted in the oncology institute that related to the specialized medical centers, that provide oncology treatment for patient in different ages(children-adult-elderly). which was the only health-care setting providing health-care services to oncology patient in El-Minya region. There are 21 beds in the chemical department, 15 beds for the oncology department and 18 beds for the external department. Patient interviewed in the out-patient clinic" "one room for female patients ".

\section{Sample}

A randomly selected sample of women diagnosed with gynecological and breast cancers that attended the oncology institute were recruited. Total attendance per week ranged from 1-2 case for gynecological cancer and 2-3 cases for breast cancer. The total number of women included in the study was 90 women. The sample size was raised to 100 women The sample divided into two main groups 50 each study group who followed the recommended QOL improvem ent nursing intervention program and control group who followed the routine care. After acceptance of eligible women to participate in the study, they were assigned randomly to either one of the above groups. Allocation concealment was done using serially -numbered closed opaque envelope.

\section{The inclusion criteria}

1. Women undergoing treatment for gynecological cancers such as uterine, ovarian, cervical, vulvar or vaginal cancers and breast cancer over the past three months.

2. Married women aged 20-55 years .

3. Premenopausal or postmenopausal (defined by amenorrhea of $\geq 6$ months).

4. Ability to give informed consent.

\section{Exclusion criteria}

1. Additional cancer diagnoses (including metastasis).

2. Women who did not have sexual intercourse in the last month, were pregnant or delivered in the last 6 months or widowed women

\section{Tools}

Data were collected by structured interviewing questionnaire at baseline, follow up, and evaluation assessment. Assessment was conducted prior to the initial chemotherapy cycles, follow-up was conducted during subsequent chemotherapy cycle, while 
evaluation (post intervention) assessment was conducted three weeks after the last chemotherapy dose was received.Tools of the study contained five parts.

\section{Part I was to obtain}

1-a- Socio-personal data: As age, educational level, education of husband, employment, residence, family income.

1-b-Menstrual history: As age at menarche, menstrual status: "premenopausal, post-menopausal, peri- menopausal", age at marriage, period of marriage, age at first child birth, and age at last child birth.

1-c- clinical characteristics: include Information about disease site (breast vs. gynecological), stage at diagnosis, and type of treatment which may include surgery, radiation, chemotherapy, and/or hormonal therapy.

Part II: The Reproductive Concerns scale (RCS; Wenzel et al., 2005). Was developed for female cancer patients. It was translated into Arabic by the investigator to examines concerns among survivors whose reproductive ability may have been impaired or removed due to disease and/or treatment. And consists of 14 items assessing the extent to which women viewed reproductive concerns as a problem: Items are rated on a five-point Likert scale ranging from $0=$ not at all to $4=$ very much. Items are summed for a total score (with two positively-worded items"5, $10,15 "$ reverse-scored). Scores range from 0 to 56 with a higher score indicating greater reproductive concerns and relatively poor QOL, poor satisfaction with life, and depression.

Scoring system of reproductive concerns scale:

Calculate the sum of total score of each patient, calculate total score \% for each patient (total score for the patient/maximum total score of the scale) $\mathrm{x} 100$, and Split the total score \% into:

0 - No concern about fertility,

1-little concerned $<$ mean - SD $<33 \%$

2-Somewhat concerned from (mean - sd) to (mean + sd) $33.3-66.7 \%$

3 -Very concerned $>$ mean + sd $>66.7 \%$

Women who wanted to have a baby had higher mean scores than those who did not.

Part III: Female Sexual Functionindex (FSFI; Rosen et al., 2000) Is a 19-item self-report measure.It was translated into Arabic by the investigator to assess sexual functioning during the past four weeks. Items are rated using a six-point Likert scales (e.g.; Over the past 4 weeks, how often did you feel sexual desire or interest? 5=almost always or always, $4=$ most times [more than half the time]. Principal components analysis yields six subscales: desire, arousal, lubrication, orgasm, satisfaction, and pain. Items are rated using a six- point Likert scales (e.g.; Over the past 4 weeks, how often did you feel sexual desire or interest? 5=almost always or always, $4=$ most times [more than half the time]. The total FSFI score under 26.55 was accepted as female sexual dysfunction (FSD).

Scoring system of female sexual function index: Subscale scores are calculated by adding the Likert responses and multiplying the sum by a domain factor (as specified in scoring instructions (Wiegel et al., 2005). The total score was calculated by summing the six domain scores.

1. The lowest score was calculated as 2 and the highest score as 36 .

2. The total FSFI score under 26.55 was accepted as female sexual dysfunction (FSD). It discriminates between healthy patients and those with FSD (Wiegel et al., 2005).

Part IV: Cancer-specific stress. The Impact of Events Scale - Revised (IES-R; Marmar et al, 1996) is a 22-item self-report questionnaire translated into Arabic by the investigator to assess traumatic stress reactions to cancer diagnosis and treatment. Factor analytic studies indicate that the measure assesses three factors (corresponding to the posttraumatic stress disorder "PTSD" clusters): intrusive thoughts (i.e.; "I had dreams about being a cancer patient"), avoidant thoughts/behaviors (e.g., "I tried not to talk about it [cancer]"), and hyper arousal (e.g.; "I was jumpy and easily startled"). Women rated the frequency of these feelings or events during the previous week, using a five-point Likert scale ranging from $0=$ not at all to $4=$ extremely. Items were summed for a total score that ranges from 0 to 88 , with higher scores reflecting greater cancer-related stress. Authors recommend a cut-off score of 33 for identifying patients with clinical symptoms of posttraumatic stress (Shapinsky et al., 2005).

Scoring system

On this test, scores that exceed 24 can be quite meaningful. High scores have the following associations:

- 24 or milder: PTSD": PTSD is a clinical concern. Those with scores that is high who do not have full PTSD will have partial PTSD or at least some of the symptoms (Asukai \& Kato, 2002 ).

- 33 and above moderate "PTSD": This represents the best cutoff for a probable diagnosis of PTSD(Creamer et al., 2002).

- 37 or more "sever PTSD": This is high enough to suppress women immune system's functioning (even 10 years after an impact event (Kawamura et al., 2001).

Part V: Quality of life, The Traditional Chinese version of the Functional Assessment of Cancer Therapy-General (TCHI FACT-G, (Cella, 1997) Version 4 translated into Arabic by the investigator to 
be used in measurement of the impact of gynecological and breast cancer and related treatment on patients' QOL. The original version of the FACT-G is a generic core questionnaire in the Functional Assessment of Chronic Illness Therapy (FACIT) measurement system. It is considered appropriate for use with patients with any form of cancer (Cella, 1997).

The TCHI FACT-G Version 4 includes 27 items and covers four primary QOL domains: physical wellbeing (PWB; 7 items), emotional well-being (EWB; 6 items), social well-being (SWB; 7 items) and functional well-being (FWB; 7 items (." A five-point Likert scale was used $(0=$ not at all, $1=$ a little bit, 2 = somewhat, 3 = quite a bit, 4 = very much), which provided four subscale scores and a total score ranging from 0 to 108 , a higher score meaning high QOL, and low effect of gynecological and breast cancer treatment on QOL (Lau et al., 2002).

*Scoring system of functional assessment of cancer therapy-general

- $0-33 \% \rightarrow$ Mild affection "good QOL"

- $33.3-66.7 \% \rightarrow$ Moderate affection "average QOL"

- $\quad>66.7 \% \rightarrow$ severe affection "poor QOL".

Quality Of Life Improvement nursing intervention Program

The component of information provision provides thorough, accurate and useful information on a women illness, treatment and self-care QOL. Quality of life is a broad multidimensional concept that considers a person's physical, emotional, social, and spiritual well-being (figure 3). According to data from the National Health Interview Survey, approximately 1 in 4 cancer survivors reports a decreased QOL due to physical problems and 1 in 10 due to emotional problems (Weaver et al.,2012).

Women in the nursing intervention group received tailored specialized care. The primary objective of the intervention was to assist women in developing and maintaining self-management skills and to facilitate their active participation in decisions affecting their subsequent treatment. Nursing interventions included symptoms assessment, management monitoring, and emotional support, and women education, coordination of resources, referrals, and direct nursing care through individualized symptom management program.

\section{Content of guidance booklet}

1. Introduction about gynecological: definition, and treatment modalities for gynecological and breast cancer.

2. Overview of treatment modalities and the most common side effects and the necessary nursing measures to manage it: as anemia, leukopenia, low platelet count, nausea, vomiting, diarrhea, anorexia, fatigue, anxiety ,urinary incontinence, depression, alopecia, disturbed body image, sexual dysfunction, infertility, and menopause.

3. Quality of life and effect of gynecological \& breast cancer on QOL.

4. Screening measures for prevention and early detection of metastasis to other organs as information about Pap smear, mammogram, and breast self-examination. Each of this content was supported with suitable figures simple knowledge in Arabic language in about 30 pages.

\section{Content validity}

There is no new version for any scale of the study, also all the study scales were translated by the investigator so required a test for validity and reliability . Also the functional assessment of cancer therapy-general to assess QOL has no scoring system. The investigator distributed the questionnaire to a panel of five specialists in obstetrics and gynecology nursing, oncology nursing staff, and medical related specialists in Beni suef and Assiut University to check the validity of the tool used.

Pilot study

A pilot study was implemented on $10 \%$ of women included in the study which was equal to (10 women) to ascertain the relevance of the tools, and estimate the length of the time needed to fill the sheet. Analysis of the pilot study revealed that minor modifications are required. These modifications were done and women included in the pilot study were included in the total sample.

\section{Procedures}

Once the permission was granted to proceed with the proposed study, oral consent was obtained from each woman. The investigator initiated data collection. By reviewing the visits appointment in the selected setting of the study. The researcher interviewed the women face to face in the day of visit in the Oncology institute at El-Minya city "outpatient clinic", waiting room 2 days per week from 9 a.m. to 2 p.m during the period from January 2016 to June 2017. Collection of data was from the control group who received routine care and the study group who received assessment and nursing intervention. The flow of intervention was through 5 sessions (may be less) for women received small number of doses with the average of one session every three weeks (30 minute each session) for four phases of nursing intervention program (pre and post). Data was collected through interviewing, assessment, implementation, and follow up \& evaluation phases.

A. Interviewing phase; the investigator introduced herself and briefly explained the study to women who meet the criteria for inclusion in the study. 
Interviewing was carried out during the first visit and each interview lasted for 10 minutes.

B. Assessment. The baseline (pre-intervention) assessment was conducted prior to the first or second chemotherapy cycles, Each session, the investigator recorded the side effects of chemotherapy after previous dose (follow-up sheet).Standardized measures used to measure the variables judged to be central to predict QOL as reproductive concerns, sexual function, cancerspecific stress, and Functional assessment of cancer therapy on patients' QOL (Ruth et al, 2009).

C. Implementation (QOL improvement nursing intervention program). The investigator applied QOL improvement nursing intervention program for the women under investigation after obtaining baseline assessment data.The main component of the nursing intervention program was therefore information provision related to knowledge of cancer, impacts of cancer treatment and self-care. Women were able to become familiar with the illness event and related symptoms, as well as received informational support and advice to solve a problem. Moreover, beliefs and values in sexuality, child-birth, and menopausal transition were clarified, education on the psychological aspect, dietary advice and exercise. Behavior therapy consisted of stress management * relaxation and deep breathing exercises, coping skills, and Kegel's exercises. Psychological support was solely provided in the form of counseling which focused on emotional support. The program carried out in the form of individualized nursing intervention sessions, while a handout was used to facilitate the process of education; each session took about 20 minute. Any clarification needed for the women was given by the investigator. At the beginning of the first session an orientation of nursing intervention was taken place .Each session started with a summary of the previous one. To ensure exposure of all women to the same learning experience, all women received the nursing intervention content using simple teaching methods as discussion, demonstration and re-demonstration. Suitable teaching aids specially prepared for the nursing intervention was used as printed materials and posters.

D. Follow up and evaluation phase. Women was contacted in the day of visit in the Oncology institute to be followed up after three weeks from initial visit and for average of five times with three weeks interval and this was done by using follow up sheet (oncology treatment side effects record). Moreover, women were instructed to return the Oncology institute at any time they experience any problems and referral system was carried out. Evaluation was applied after the program through administration of evaluation questionnaires to measure the effectiveness of nursing intervention program on sexual function, stress reduction, and QOL improvement.

Ethical considerations:

$\checkmark \quad$ The ethical research consideration in this study included the following: Research proposal was approved from ethical committee in the faculty of nursing in Assiut University. The study followed common ethical principles in clinical research. There was no risk for study subject during application of the research. Oral consent was obtained from patients or guidance that for willing to participate in the study, after explaining the nature and purpose of the study.Confidentiality and anonymity was assured.

\section{Statistical Analysis}

All the statistical analysis was performed using SPSS package version 20. Collected data were coded and analyzed. Descriptive statistics for the variables were calculated.

\section{Inferential Statistics}

The data were tested for normality using the Anderson-Darling test and for homogeneity variances prior to further statistical analysis. Categorical variables were described by number and percent $(\mathrm{N}$, $\%$ ), where continuous variables described by mean and standard deviation (Mean, SD). Chi-square test used to compare between categorical variables where compare between continuous variables by paired and unpaired ttest. Pearson correlation coefficient used to assess the association between continuous scales. A two-tailed $\mathrm{p}$ $<0.05$ was considered statistically significant. All analyses were performed with the IBM SPSS20 software. 


\section{Results}

Table (1): Distribution of the Studied Women According to Their Socio-personal Characteristics.

\begin{tabular}{|c|c|c|c|c|c|}
\hline \multirow{2}{*}{ Variable } & \multicolumn{2}{|c|}{ Study $(n=50)$} & \multicolumn{2}{|c|}{ Control $(n=50)$} & \multirow{2}{*}{ P. value } \\
\hline & No. & $\%$ & No. & $\%$ & \\
\hline \multicolumn{6}{|l|}{ Age groups } \\
\hline $20-29$ years & 4 & 8.0 & 6 & 12.0 & \multirow{4}{*}{0.093} \\
\hline 30-39 years & 18 & 36.0 & 9 & 18.0 & \\
\hline $40-49$ years & 25 & 50.0 & 26 & 52.0 & \\
\hline 50- 55 years & 3 & 6.0 & 9 & 18.0 & \\
\hline Age (mean \pm SD) years & \multicolumn{2}{|c|}{$39.5 \pm 7.19$} & \multicolumn{2}{|c|}{$41 \pm 8.32$} & 0.337 \\
\hline \multicolumn{6}{|l|}{ Educational level } \\
\hline Illiterate & 25 & 50.0 & 25 & 50.0 & \multirow{4}{*}{0.490} \\
\hline Read and write & 8 & 16.0 & 9 & 18.0 & \\
\hline Secondary education & 11 & 22.0 & 14 & 28.0 & \\
\hline Higher education & 6 & 12.0 & 2 & 4.0 & \\
\hline \multicolumn{6}{|l|}{ Occupation } \\
\hline Working & 5 & 10.0 & 4 & 8.0 & \multirow{2}{*}{0.727} \\
\hline Housewife & 45 & 90.0 & 46 & 92.0 & \\
\hline \multicolumn{6}{|l|}{ Residence } \\
\hline Urban & 19 & 38.0 & 15 & 30.0 & \multirow{2}{*}{0.398} \\
\hline Rural & 31 & 62.0 & 35 & 70.0 & \\
\hline \multicolumn{6}{|l|}{ Income (from their point of view). } \\
\hline Enough & 27 & 54.0 & 21 & 42.0 & \multirow{2}{*}{0.230} \\
\hline Not enough & 23 & 46.0 & 29 & 58.0 & \\
\hline Age at first child birth / years & \multicolumn{2}{|c|}{$21.15 \pm 3.39$} & \multicolumn{2}{|c|}{$19.77 \pm 5.35$} & 0.061 \\
\hline Age at last child birth in years & \multicolumn{2}{|c|}{$30.23 \pm 5.08$} & \multicolumn{2}{|c|}{$29.19 \pm 6.75$} & 0.395 \\
\hline \multicolumn{6}{|l|}{ Menstrual status } \\
\hline Premenopausal & 24 & 48 & 22 & 44 & \multirow{3}{*}{0.551} \\
\hline Postmenopausal & 6 & 12 & 10 & 20 & \\
\hline Peri- menopausal & 20 & 40 & 18 & 36 & \\
\hline $\begin{array}{l}\text { Number of living children (mean } \\
\pm \mathrm{SD} \text { ) of children }\end{array}$ & \multicolumn{2}{|c|}{$3.48 \pm 1.34$} & \multicolumn{2}{|c|}{$4.04 \pm 1.76$} & 0.081 \\
\hline
\end{tabular}

- Chi square test for qualitative data between the two groups $\quad$ N.S = Non-significant at $p>0.05$

at $p<0.05 \quad * *$ Moderate significant at $p<0.01 \quad * * *$ highly significant at $p<0.001$

Table (2): Distribution of the studied women according to their clinical characteristics of diagnosis.

\begin{tabular}{|c|c|c|c|c|c|}
\hline & \multicolumn{2}{|c|}{$\operatorname{Study}(n=50)$} & \multicolumn{2}{|c|}{$\operatorname{Control}(n=50)$} & \multirow[t]{2}{*}{ P. value } \\
\hline & No. & $\%$ & No. & $\%$ & \\
\hline \multicolumn{6}{|l|}{ Stage at diagnosis } \\
\hline Stage I & 7 & 14.0 & 3 & 6.0 & \multirow{4}{*}{0.217} \\
\hline Stage II & 11 & 22.0 & 6 & 12.0 & \\
\hline Stage II & 3 & 6.0 & 4 & 8.0 & \\
\hline Stage IV & 29 & 58.0 & 35 & 70.0 & \\
\hline \multicolumn{6}{|l|}{ Site of tumor } \\
\hline Breast & 32 & 64 & 32 & 64 & \multirow{2}{*}{1} \\
\hline Gynecological & 18 & 36 & 18 & 36 & \\
\hline \multicolumn{6}{|c|}{$\begin{array}{l}\text { Gynecological cancer } \\
\text { categories ( } n=18 \text { for each group) }\end{array}$} \\
\hline - Ovarian cancer & 2 & 11.1 & 1 & 5.5 & 0.514 \\
\hline - Endometrial cancer & 7 & 38.3 & 10 & 55.5 & 0.127 \\
\hline - Utero-ovarian cancer & 8 & 44.4 & 7 & 38.3 & 0.677 \\
\hline - Cancer of the Vulva & 1 & 5.5 & 0 & 0 & 0.284 \\
\hline
\end{tabular}




\begin{tabular}{|l|c|c|c|c|c|}
\hline Treatment received\# & & & & & \\
\hline Surgery & 32 & 64 & 45 & 90 & $\mathbf{0 . 0 0 2} *$ \\
\hline Chemotherapy & 48 & 96 & 50 & 100 & 0.153 \\
\hline Radiotherapy & 17 & 34 & 14 & 28 & 0.517 \\
\hline Hormonal therapy & 3 & 6 & 2 & 4 & 0.646 \\
\hline
\end{tabular}

Table (3): Distribution of the studied women according to their reproductive concerns at the first visit.

\begin{tabular}{|l|c|c|c|}
\hline Reproductive Concerns scale [RCS] & Cases $(\mathbf{n}=\mathbf{5 0})$ & Control $(\mathbf{n = 5 0})$ & P value \\
\hline RCS total & $(27.8-78.9)$ & $(25.6-77.8)$ & \\
Range & $48.9 \pm 13.7$ & $46.7 \pm 13.3$ & 0.420 \\
Mean \pm SD & 44.4 & 43.3 & \\
Median & $0(0 \%)$ & $1(2 \%)$ & \\
\hline RCS total & $35(70 \%)$ & $36(72 \%)$ & 0.824 \\
Little concerned & $15(30 \%)$ & $13(26 \%)$ & \\
Somewhat concerned & Very concerned & & \\
\hline
\end{tabular}

Mann Whitney test for non-parametric quantitative data between the two groups N.S = Non-significant at $p>0.05$ $*$ Mild significant at $p<0.05 \quad * *$ Moderate significant at $p<0.01 \quad * * *$ highly significant at $p<0.001$

Table (4): Distribution of the studied women according to sexual function at first and last visit.

\begin{tabular}{|c|c|c|c|c|c|c|}
\hline \multirow{2}{*}{$\begin{array}{c}\text { Female Sexual } \\
\text { Function index[FSFI] }\end{array}$} & \multicolumn{2}{|c|}{ Pre" at the first visit" } & \multirow{2}{*}{$P$ value } & \multicolumn{2}{|c|}{ Post "at the last visit" } & \multirow{2}{*}{$P$ value } \\
\hline & Study $(n=50)$ & control $(n=50)$ & & Study $(n=50)$ & Control $(n=50)$ & \\
\hline $\begin{array}{l}\text { Total score } \\
\text { Range } \\
\text { Mean } \pm \text { SD } \\
\text { Median }\end{array}$ & $\begin{array}{c}(0.6-30.6) \\
12.1 \pm 10.2 \\
14.6\end{array}$ & $\begin{array}{c}(0.6-28) \\
11.4 \pm 10.5 \\
12.7\end{array}$ & 0.736 & $\begin{array}{c}(0.6-31) \\
20.4 \pm 9.2 \\
23.7\end{array}$ & $\begin{array}{c}(0.6-28.9) \\
10.7 \pm 10.4 \\
11.7 \\
\end{array}$ & $<0.001 * *$ \\
\hline $\begin{array}{l}{ }^{(\$)} \text { Female sexual } \\
\text { Dysfunction [FSD] } \\
\text { Absent } \\
\text { Present }\end{array}$ & $\begin{array}{c}3(6 \%) \\
47(94 \%)\end{array}$ & $\begin{array}{c}3(6 \%) \\
47(94 \%)\end{array}$ & 1.000 & $\begin{array}{l}13(26 \%) \\
37(74 \%)\end{array}$ & $\begin{array}{c}2(4 \%) \\
48(96 \%)\end{array}$ & $0.003 * *$ \\
\hline
\end{tabular}

Wilcoxon Signed rank test for non-parametric quantitative data within each group

(\$)McNemar test for repeated measure qualitative data $\quad$ N.S=Non-significant at $p>0.05 \quad *$ Mild significant at $p<0.05$

** Moderate significant at $p<0.01 \quad * * *$ highly significant at $p<0.001$

Table (5): Distribution of the studied women according to cancer specific stress at first and last visit.

\begin{tabular}{|c|c|c|c|c|c|c|}
\hline \multirow[b]{2}{*}{ Cancer-specific stress[CSS] } & \multicolumn{3}{|c|}{ Pre" at the first visit" } & \multicolumn{3}{|c|}{ Post "at the last visit" } \\
\hline & $\begin{array}{c}\text { Study group } \\
(\mathbf{n}=\mathbf{5 0})\end{array}$ & $\begin{array}{c}\text { Control group } \\
(\mathbf{n}=\mathbf{5 0})\end{array}$ & $P$ value & $\begin{array}{c}\text { Study group } \\
(\mathbf{n}=50)\end{array}$ & $\begin{array}{c}\text { Control group } \\
(n=50)\end{array}$ & $P$ value \\
\hline $\begin{array}{l}\text { Cancer-specific } \\
\text { stress }[\text { CSS] } \\
\text { Range } \\
\text { Mean } \pm \text { SD } \\
\text { Median }\end{array}$ & $\begin{array}{c}(4-88) \\
52.1 \pm 19.5 \\
53.5\end{array}$ & $\begin{array}{c}(17-74) \\
52.8 \pm 15.5 \\
55.5\end{array}$ & 0.842 & $\begin{array}{c}(2-62) \\
26.4 \pm 13.9 \\
26\end{array}$ & $\begin{array}{c}(6-74) \\
46 \pm 17.6 \\
48.5\end{array}$ & $<0.001 *$ \\
\hline $\begin{array}{l}{ }^{(\$)} \text { Cancer-specific } \\
\text { stress[CSS] } \\
\text { No } \\
\text { Mild } \\
\text { Moderate } \\
\text { Severe }\end{array}$ & $\begin{array}{c}4(8 \%) \\
6(12 \%) \\
0(0 \%) \\
40(80 \%)\end{array}$ & $\begin{array}{c}3(6 \%) \\
5(10 \%) \\
0(0 \%) \\
42(84 \%)\end{array}$ & 0.868 & $\begin{array}{c}23(26 \%) \\
12(24 \%) \\
5(10 \%) \\
10(20 \%)\end{array}$ & $\begin{array}{c}5(10 \%) \\
9(18 \%) \\
2(4 \%) \\
34(68 \%)\end{array}$ & $<0.001 *$ \\
\hline
\end{tabular}

Wilcoxon Signed rank test for non-parametric quantitative data within each group

(\$)McNamara test for repeated measure qualitative data $\quad$ N.S $=$ Non-significant at $p>0.05 \quad *$ Mild significant at $p<0.05$

** Moderate significant at $p<0.01 \quad * * *$ highly significant at $p<0.001$ 
Table (6): Distribution of the studied women according to cancer quality of life at first and last visit.

\begin{tabular}{|c|c|c|c|c|c|c|}
\hline \multirow[b]{2}{*}{ Quality of life [QOL] } & \multicolumn{3}{|c|}{ Pre "at the first visit" } & \multicolumn{3}{|c|}{ Post "at the last visit" } \\
\hline & $\begin{array}{c}\text { Study group } \\
(\mathrm{n}=\mathbf{5 0})\end{array}$ & $\begin{array}{c}\text { Control grou } \\
(n=50)\end{array}$ & P value & $\begin{array}{c}\text { Study group } \\
(\mathbf{n}=\mathbf{5 0})\end{array}$ & $\begin{array}{c}\text { Control grou } \\
(\mathbf{n}=\mathbf{5 0})\end{array}$ & $P$ value \\
\hline $\begin{array}{l}\text { Total score } \\
\text { Range } \\
\text { Mean } \pm \mathrm{SD} \\
\text { Median } \\
\end{array}$ & $\begin{array}{c}(21-94) \\
51 \pm 18 \\
47\end{array}$ & $\begin{array}{c}(18-88) \\
51.3 \pm 18.7 \\
50 \\
\end{array}$ & 0.944 & $\begin{array}{c}(41-103) \\
80.2 \pm 16.1 \\
84.5 \\
\end{array}$ & $\begin{array}{c}(15-86) \\
48.1 \pm 19.8 \\
47\end{array}$ & $0.001 * *$ \\
\hline $\begin{array}{l}\text { Quality of life } \\
\text { Poor } \\
\text { Moderate } \\
\text { good }\end{array}$ & $\begin{array}{c}10(20 \%) \\
32(64 \%) \\
8(16 \%)\end{array}$ & $\begin{array}{c}11(22 \%) \\
31(62 \%) \\
8(16 \%)\end{array}$ & 0.969 & $\begin{array}{c}0(0 \%) \\
14(28 \%) \\
36(72 \%)\end{array}$ & $\begin{array}{c}13(26 \%) \\
29(58 \%) \\
8(16 \%)\end{array}$ & $.000 *$ \\
\hline
\end{tabular}

Wilcoxon Signed rank test for non-parametric quantitative data within each group $\quad$ N.S = Non-significant at $p>0.05$

$*$ Mild significant at $p<0.05 \quad * *$ Moderate significant at $p<0.01 \quad * * *$ highly significant at $p<0.001$

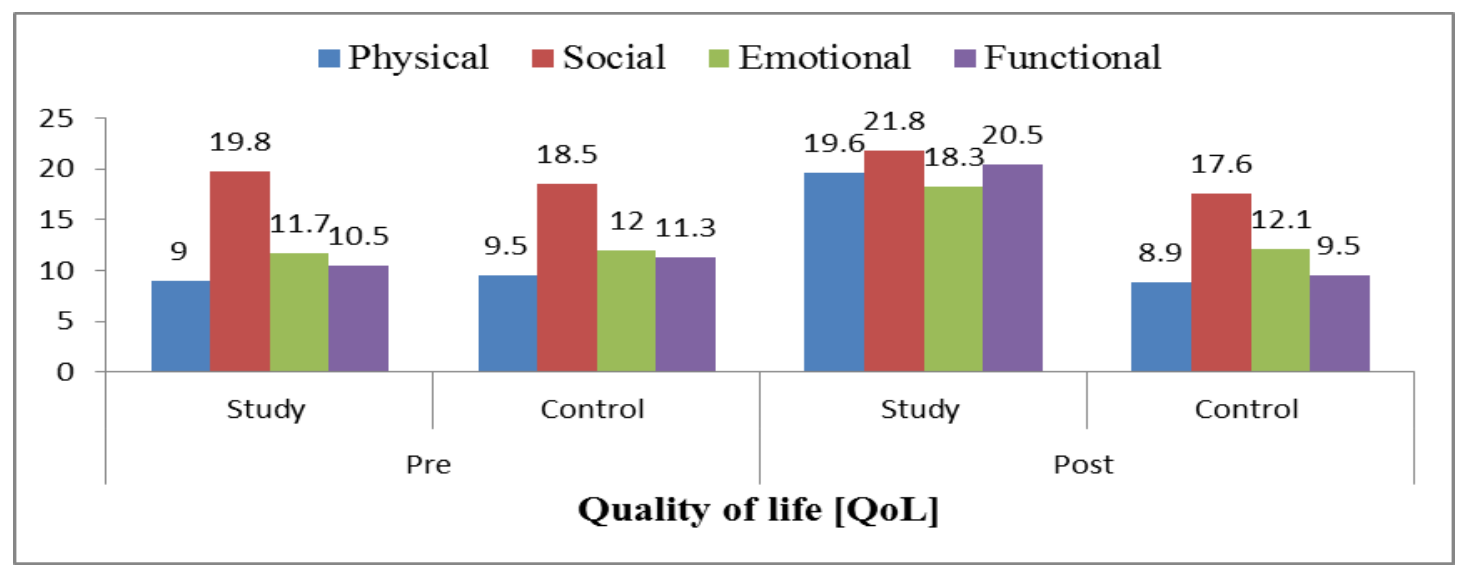

Figure (1): Distribution of the studied women according to subscales (domains) of cancer quality of life at first and last visit/mean.

Table (7): Distribution of the study group according to impact of the nursing intervention program on sexual function, cancer specific stress, and quality of life.

\begin{tabular}{|c|c|c|c|}
\hline & \multicolumn{2}{|c|}{ Study group } & \multirow{2}{*}{$P$ value } \\
\hline & Pre $(n=50)$ & Post $(n=50)$ & \\
\hline \multicolumn{4}{|c|}{ Female Sexual Function index[FSFI] } \\
\hline $\begin{array}{l}\text { Total score } \\
\text { Range } \\
\text { Mean } \pm \text { SD } \\
\text { Median } \\
\end{array}$ & $\begin{array}{c}(0.6-30.6) \\
12.1 \pm 10.2 \\
14.6 \\
\end{array}$ & $\begin{array}{c}(0.6-31) \\
20.4 \pm 9.2 \\
23.7\end{array}$ & $0.014 *$ \\
\hline $\begin{array}{l}(\$) \text { FSD } \\
\text { No } \\
\text { Yes }\end{array}$ & $\begin{array}{c}3(6 \%) \\
47(94 \%)\end{array}$ & $\begin{array}{l}13(26 \%) \\
37(74 \%)\end{array}$ & $0.002 *$ \\
\hline \multicolumn{4}{|l|}{ Cancer-specific stress[CSS] } \\
\hline $\begin{array}{l}\text { CSS } \\
\text { Range } \\
\text { Mean } \pm \text { SD } \\
\text { Median } \\
\end{array}$ & $\begin{array}{c}(4-88) \\
52.1 \pm 19.5 \\
53.5 \\
\end{array}$ & $\begin{array}{c}(2-62) \\
26.4 \pm 13.9 \\
26 \\
\end{array}$ & $<0.001 *$ \\
\hline $\begin{array}{cl}\text { (\$) CSS }^{(1)} & \\
- & \text { No[PTSD] } \\
- & \text { Mild[PTSD] } \\
- & \text { Moderate[PTSD] } \\
- & \text { Severe[PTSD] }\end{array}$ & $\begin{array}{c}4(8 \%) \\
6(12 \%) \\
0(0 \%) \\
40(80 \%)\end{array}$ & $\begin{array}{c}23(26 \%) \\
12(24 \%) \\
5(10 \%) \\
10(20 \%)\end{array}$ & $<0.001 *$ \\
\hline
\end{tabular}




\begin{tabular}{|l|c|c|c|}
\hline \multirow{2}{*}{} & \multicolumn{2}{|c|}{ Study group } & \multirow{2}{*}{ P value } \\
\cline { 2 - 3 } & Pre $(\mathbf{n}=\mathbf{5 0})$ & Post $(\mathbf{n}=\mathbf{5 0})$ & \\
\hline Total score & & & \multirow{2}{*}{. } \\
Range & $(21-94)$ & $(41-103)$ & \\
Mean \pm SD & $51 \pm 18$ & $80.2 \pm 16.1$ & 84.5 \\
Median & 47 & & \\
\hline
\end{tabular}

N.S $=$ Non-significant at $\mathrm{p}>0.05$

$* * *$ highly significant at $\mathrm{p}<0.001$

*Mild significant at $\mathrm{p}<0.05 \quad * *$ Moderate significant at $\mathrm{p}<0.01$

Table (8): The relationship between the studied women quality of life (dependent), socio-demographic data, social stressors, and clinical characteristics (independents).

\begin{tabular}{|c|c|c|c|c|c|c|c|c|}
\hline \multirow{3}{*}{$\begin{array}{l}\text { Quality of life } \\
\text { FACT-G }\end{array}$} & \multicolumn{4}{|c|}{ Pre "at the first visit" } & \multicolumn{4}{|c|}{ Post "at the last visit" } \\
\hline & \multicolumn{2}{|c|}{ Study group } & \multicolumn{2}{|c|}{ Control group } & \multicolumn{2}{|c|}{ Study group } & \multicolumn{2}{|c|}{ Control group } \\
\hline & $\mathbf{r}$ & P value & $\mathbf{r}$ & P value & $\mathbf{r}$ & $P$ value & $\mathbf{r}$ & P value \\
\hline \multicolumn{9}{|c|}{ Socio-personal data } \\
\hline Age & 0.257 & 0.072 & -0.002 & 0.990 & 0.161 & 0.263 & 0.080 & 0.579 \\
\hline Residence (Rural) & -0.060 & 0.679 & -0.061 & 0.676 & -0.007 & 0.961 & -0.209 & 0.146 \\
\hline Educational level & -0.208 & 0.147 & 0.247 & 0.083 & -0.187 & 0.194 & 0.133 & 0.357 \\
\hline $\begin{array}{l}\text { Education of } \\
\text { husband }\end{array}$ & -0.142 & 0.324 & 0.447 & $0.001 *$ & -0.120 & 0.407 & 0.216 & 0.132 \\
\hline Occupation & 0.012 & 0.937 & -0.153 & 0.287 & -0.102 & 0.482 & -0.163 & 0.257 \\
\hline $\begin{array}{l}\text { Occupation of } \\
\text { husband }\end{array}$ & -0.149 & 0.303 & 0.118 & 0.413 & -0.232 & 0.105 & 0.072 & 0.618 \\
\hline Income & 0.023 & 0.873 & 0.344 & $0.014 *$ & 0.020 & 0.889 & 0.274 & 0.054 \\
\hline Age at menarche & -0.100 & 0.492 & 0.051 & 0.723 & 0.206 & 0.150 & -0.156 & 0.278 \\
\hline Age at marriage & -0.151 & 0.296 & -0.109 & 0.451 & -0.185 & 0.198 & -0.116 & 0.421 \\
\hline Period of marriage & 0.219 & 0.127 & 0.070 & 0.631 & 0.147 & 0.308 & 0.123 & 0.395 \\
\hline $\begin{array}{l}\text { Age at first child } \\
\text { birth }\end{array}$ & -0.059 & 0.691 & -0.168 & 0.253 & -0.087 & 0.555 & -0.003 & 0.986 \\
\hline $\begin{array}{l}\text { Age at last child } \\
\text { birth }\end{array}$ & 0.160 & 0.276 & -0.047 & 0.750 & -0.019 & 0.897 & 0.050 & 0.738 \\
\hline $\begin{array}{l}\text { Menstrual status } \\
\text { Menopause }\end{array}$ & 0.125 & 0.386 & 0.041 & 0.777 & 0.043 & 0.769 & -0.160 & 0.268 \\
\hline \multicolumn{9}{|l|}{ Social stressors } \\
\hline $\begin{array}{l}\text { Children Lower } \\
\text { than } 15 \text { years }\end{array}$ & 0.026 & 0.858 & 0.074 & 0.60 & -0.109 & 0.452 & -0.051 & 0.727 \\
\hline $\begin{array}{l}\text { Financial } \\
\text { stressors or debts }\end{array}$ & 0.201 & 0.163 & -0.248 & 0.08 & -0.149 & 0.301 & -0.153 & 0.288 \\
\hline Emotional illness & 0.116 & 0.423 & -0.153 & 0.29 & -0.112 & 0.439 & 0.104 & 0.472 \\
\hline Chronic diseases & -0.016 & 0.911 & -0.147 & 0.30 & -0.144 & 0.317 & 0.113 & 0.436 \\
\hline $\begin{array}{l}\text { Problems related } \\
\text { to chronic drug } \\
\text { intake }\end{array}$ & 0.107 & 0.457 & -0.127 & 0.38 & -0.134 & 0.352 & 0.102 & 0.480 \\
\hline \multicolumn{9}{|c|}{ Clinical characteristics } \\
\hline $\begin{array}{l}\text { Stage at } \\
\text { diagnosis }\end{array}$ & -0.271 & 0.234 & -0.523 & 0.04 & 0.056 & 0.809 & -0.202 & 0.470 \\
\hline Site of tumor & -.109 & .451 & -.030 & .83 & .149 & .302 & -.251 & .079 \\
\hline $\begin{array}{l}\text { Surgical } \\
\text { treatment }\end{array}$ & 0.101 & 0.485 & 0.023 & 0.87 & 0.220 & 0.126 & 0.180 & 0.210 \\
\hline Chemotherapy & -0.025 & 0.864 & $\begin{array}{ll}--- \\
\end{array}$ & --- & 0.294 & 0.038* & ---- & ---- \\
\hline Radiotherapy & 0.026 & 0.856 & 0.045 & 0.75 & -0.006 & 0.968 & 0.134 & 0.352 \\
\hline $\begin{array}{l}\text { Hormonal } \\
\text { therapy }\end{array}$ & 0.085 & 0.559 & -0.060 & 0.67 & -0.219 & 0.127 & -0.025 & 0.864 \\
\hline
\end{tabular}

Non-parametric Spearman's rho correlation N.S $=$ Non-significant at $p>0.05$

$* *$ Moderate significant at $p<0.01 \quad * * *$ highly significant at $p<0.001$ 
Table (1): No statistical significant difference was found between the two groups which denote homogeneity of the groups. The age range of the studied women was between 20 to 55 years. The mean age of the women in the study group was $39.5 \pm 7.19$ years as compared with $41 \pm 8.32$ years in the control group, and half of studied women in both groups were in the age range of (40-49 years). Half of the studied women in both groups were illiterate, majority of them in both groups were housewives. Near to two thirds of the women in study vs. (72\%) in the control groups lives in rural areas. More than half of women of the study group reported enough income and $(58.0 \%)$ of the control group reported insufficient income.

Table (2): Illustrates no statistical significant difference regarding to stage of cancer, as more than half of the study group vs. more than two thirds of the control group were in stage IV of disease. Regarding to site of tumor $(64.0 \%)$ of both the study and control group had breast cancer, and (36\%) of the study and control group had gynecological cancer, this intended to gain homogeneity between the two groups. There was a highly statistical significant difference regarding treatment received as $64 \%$ of the study group vs. (90\%) of the control group received surgical treatment.

Table (3): Illustrates that more than two thirds of the study group and the control group were somewhat concerned about fertility, and the mean of reproductive concerns was approximately similar with no statistical significant difference.

Table (4): Demonstrates that there was no statistically significant difference between the two group at the first visit, the percentage of women with sexual dysfunction was (94\%) in the two groups. At the last visit, there was a statistical significant difference in relation to impact of the nursing intervention program on sexual function, as the percentage of women with sexual dysfunction was $(74 \%)$ in the study group vs. $(96 \%)$ in the control group. ( $\mathrm{p}<0.001,0.003$ respectively).

In relation cancer specific stress in the first visit, table (5): Reveals more than three quarters of the study group had severe traumatic stress disorder , while $(8.0 \%)$ of the women were healthy with no stress . while in the control group the majority of the cases had severe traumatic stress disorder, while the healthy women with no stress were $(6.0 \%)$, with no statistically significant difference $(\mathrm{p}>0.05)$.

In the last visit there was clear effect of the nursing intervention program on traumatic stress reactions to cancer diagnosis and treatment. As $(20 \%)$ of the study group, had severe traumatic stress disorder, $(26.0 \%)$ of the women were healthy with no stress. As compared with $(68.0 \%)$ of the control group had severe traumatic stress disorder, while the healthy women with no stress were $(10 \%)$. with a highly statistical significant difference $(\mathrm{p}=<0.001 *)$.

Table (6): Reveals near to two thirds of the study group vs. (62\%) of the control group had moderate QOL, and (16\%) of the two groups had good QOL in the first visit with no statistically significant difference $(\mathrm{p}>0.05)$.

In the last visit there was clear effect of the nursing intervention program on cancer specific QOL. As (72\%) of the study group as compared with (16\%) of the control group had good QOL and $(0 \%)$ of the study group vs. (26\%) of the control group had poor QOL.

Figure (1): Demonstrates that there was no statistical significant difference on any subscales of functional assessment of cancer therapy-general between the two groups in the first visit ( $p>0.05)$. after implementation of the program a highly statistical significant difference appeared in the improvement of study group physical, social, emotional, and finally functional well-being subscales of cancer therapy-general ( $p<0.001)$.

Table (7): Reveals the positive impact of the nursing intervention program with statistical significant difference, and it is demonstrated on sexual function, as the percentage of women with sexual dysfunction decreased from $(94 \%)$ to $(74 \%)$, and the percentage of women who were healthy (have no sexual dysfunction increased from (6\%) to $(26 \%),(\mathrm{p}=<0.001 *)$. Related to cancer-specific stress in the first and last follow-up visits among the study group, more than three quarters of the study group had severe traumatic stress disorder pre administration of the program and decreased to $(20 \%)$, while the healthy women with no stress increased from $(8.0 \%)$ to $(26.0 \%)$ after administration of the program. $(\mathrm{p}=<0.001 *)$. the mean QOL increased from $51 \pm 18$ pre administration of the program to $80.2 \pm 16.1$ after administration of the program.

Table (8): Revealed that there is no significant correlation between socio-personal data and QOL as regards study and control groups of the studied women except on the control group; income was a significant predictor of positive effect on QOL during the first visit $(\mathrm{r}=0.344, \mathrm{p}<0.05)$. Regarding the clinical characteristics, in the control group stage at diagnosis was a significant predictor of negative effect on QOL during the first visit $(r=-0.523$, $\mathrm{p}<0.05)$. While in the study group, receiving chemotherapy was a significant predictor of positive effect on QOL at the last visit $(r=0.294$, $\mathrm{p}<0.05)$. 


\section{Discussion}

The therapeutic approach of patients with breast and gynecological cancer involves a high degree of concern regarding their survival (Regino et al., 2017) Due to the dramatic increase in the number of survivors living five years post-diagnosis, there has been greater recognition given to the ongoing sequelae of cancer and its impact on HRQOL (Aziz, 2007).

According to the studied women socio-personal characteristics, the result of present study showed that no statistical significant difference between the two groups which denote homogeneity of the groups.

For women with gynecological cancer, reproductive concerns may vary not only by site of disease but also by the presentation and manifestation of the disease. Gynecological cancer can present before childbearing has been started or completed, during pregnancy, or can even arise out of pregnancy, as is the case with gestational trophoblastic disease. Regarding to reproductive concerns, the results of this study indicated that more than two thirds of the study and control group were somewhat concerned about fertility. Also, according to site of tumor more than seventy percent of the studied women with breast and gynecological caner were somewhat concerned about fertility.

These findings aren't consistent with Ruddy, (2014) in Aurora who studied fertility concerns and preservation strategies in young women with breast cancer and found that almost half of the studied women reported no concern about fertility and small percent were somewhat concerned about fertility. For instance, according to current study some women may view their childbearing plans as completed, or/and due to the fact that they usually face with unhealthy feelings and due to failure to comply with major life issues, they focus on management of disease and related treatment side effects that affect their satisfaction of their role within the family as evidenced by personal health (it was significant predictor affecting reproductive concerns of the study group), also they may ignore to talk with their physician about the impact of cancer therapy on their fertility before starting treatment .

Over the last few decades, researchers have recognized the need to view cancer in a relationship context and a burgeoning literature involving psychosocial interventions to improve couples' coping and quality of life (QOL) has emerged (Badr \& Krebs, 2013)). The key to the effectiveness of interventions was the attempt to identify individual strengths and to improve patients' awareness and to train them on appropriate skills, because raising awareness of the problem and its related factors leads to the use of appropriate skill to solve it (Ganz et al., 2011).

In relation to sexual function, at the first visit, the vast majority of the studied women in the two groups had sexual dysfunction, with no statistically significant difference ( $p>0.05$ ). At the last visit, educational and counseling interventions, particularly those targeting sexual dysfunction, improved various aspects of sexual health, as near to three quarters of women in the study group had sexual dysfunction. Interestingly the improvement appeared in desire, arousal, lubrication, orgasm, satisfaction, and pain subscales and the total scale of sexual function of the study group of women with breast and gynecological cancer $(p<0.001)$. These findings are matched to the study of Anderson et al., (2015) in Australia who attempted to facilitate lifestyle changes to manage menopausal symptoms in women with breast cancer and found improvements in sexual function were observed in the intervention group compared to controls. But effect sizes were generally modest and of unclear clinical significance. And in line with Jeffries et al., (2006) in Canada, who studied an effective group psycho-educational intervention for improving compliance with vaginal dilation and found that, nurse-led psychosexual counseling can significantly improve sexual function in patients with gynecological cancer. Also, matching with the study of Powell et al., (2008) in San Francisco who investigated a randomized study of the effectiveness of a brief psychosocial intervention for women attending with gynecological cancer and found education and counseling for women after cancer treatment may also reduce sexual problems and improve marital relationship.

Interestingly these findings are consistent with Brotto et al., (2008) in Columbia who developed a psycho-educational intervention for sexual dysfunction in women with gynecological cancer and found that the psycho-educational intervention was associated with positive effect on sexual desire, arousal, orgasm, satisfaction, sexual distress, depression, and overall well-being.

According to the Egyptian family culture, marital relationship is a highly personal and private matter and it should be noted that sexual orientation is one of the least important aspects of life that isn't strongly related to women QOL. It is also not a factors affecting interpersonal communication. On other hand; the mean age of the women in the study group of the present study was $39.5 \pm 7.19$ years as compared with $41 \pm 8.32$ years in the control group, so sexual relation wasn't a prospective or a matter for them. 
Many of the sexual problems that women struggle with, whether it is dyspareunia, menopausal symptoms, or low libido, can be made much better with time and some intervention. In the current study the long treatment process, provide the investigator an opportunity for more contacts with the women to answer their questions and to solve their problems with empathic listening and a mutual trusting relationship for supporting and providing information to enable their problem solving, their self-care and their increased abilities to cope with the problems.

This study demonstrated that some women may prefer to avoid intercourse due to pain or anxiety, fear of cancer spread to her husband, a women's self-concept of herself as a distractive person, and /or change in body image that may lead to divorce or separation. Thus patients can have significant benefits from discussing their concerns specializing in these issues so removing anxiety about inability to resume vaginal intercourse post-treatment. Discussing this with patients can be challenging but can often reduce anxiety following treatment.

It was interesting to learn that the cancer diagnosis was indeed experienced as unexpected by the vast majority of patients with subjective judgment between the severity of the cancer-related burden already experienced and the burden expected in the future. In the last visit there was clear effect of the nursing intervention program on traumatic stress reactions to cancer diagnosis and treatment, as the percentage of women with severe traumatic stress disorder in the study group decreased to less than one quarter with a highly statistical significant difference $(p=<0.001 *)$. Also the improvement achieved in the study group of women with breast and gynecological cancer. These findings are matching with those of Loh et al., (2013) in Malaysia who studied effectiveness of a patient selfmanagement programme for breast cancer as a chronic illness and stated that the differential positive impact on depression, anxiety, and stress. Moreover in line with findings of Loizzo et al., (2010) in Texas who studied the effect of a contemplative self-healing program on QOL in women with breast and gynecological cancer and found a reduction in distress and disability among female breast and GC survivors with contemplative self-healing program.

In order to enhance psychological adjustment to cancer and its treatment the study group of this study learned to use avoidant behavior, warding off repeated thoughts about the stressful event as having cancer and receiving treatment to decrease a stress reaction. Moreover, teaching them to manage their physical and mental health problems concurrently with meeting with family members and informing them about management strategies and facilitating communication between patients and medical providers \& social workers were also vital components of the present study program.

The findings of the present research indicated that QOL of the women with breast and gynecological cancer have been enhanced under the influence of nursing intervention program and this improvement has not been only related to the total score of the QOL but also has occurred in physical, social, emotional, and functional well-being subscales. This was evidenced by the percentage of women with good QOL in the study group increased to seventy two percent with minimum increase in the control group. With a highly statistical significant difference appeared ( $p<0.001)$. These findings were concurrent with study reported by Klafke et al., (2015) in Germany who evaluated the effectiveness of an intervention involving complementary and alternative (CAM) therapies and counseling on CAM as complementing the supportive care of breast and gynecological cancer patients undergoing chemotherapy. It is hypothesized that this intervention increases HRQOL and clustered symptoms over the chemotherapy regimen and follow-up in this outpatient population. Also in consistent with findings of Shahsavari et al., (2015) who studied effect of self-care education on the QOL in patients with breast cancer and showed that QOL of the patients with breast cancer has been enhanced under the influence of self-care education. And with Loh et al., (2013) who stated that all dimensions of QOL increased significantly in the intervention group after performing a 1-month selfmanagement program compared with the control one.

Moreover, these findings aren't in line with Speck et al., (2010) in Philadelphia USA who studied changes in the body image and relationship scale following a one-year strength training trial for breast cancer survivors with or at risk for lymphedema, and found an improvement in body image perception after rehabilitative intervention (twice a week for 13 weeks), but they did not find any improvement in QOL.

Interestingly, with in line with Faller et al., (2011) who studied effects of psycho-oncologic interventions on emotional distress and QOL in adult patients with cancer: systematic review and metaanalysis and implied that, significant small posttreatment effects were found for emotional distress, anxiety, depression, and QOL Loizzo et al., (2010) confirmed that participants had significant within patient change on FACT-G, improving by a mean of 6.2 points. In addition, they reported clinically 
important improvement in emotional and functional domains and social, role-emotional, and mental health status domains on SF-36, and reducing in distress and disability among female breast and gynecological cancer survivors.

In a traditional setting with limited resources, typical of our countries, chemotherapy (mainly) regimen lasted very long (for example, 24 weeks) the studied women of the present study visited the outpatient clinic every 3 to 4 weeks that was, 6 to 8 times. It is likely that the women built a relationship with the researcher caring for her, which might also added to improvements in QOL, and due to high interest and compliance to cancer treatment, we found that majority of the studied women were able to complete the five sessions for the intervention. So that a long-term follow-up of the patients in the intervention group might well show an improvement in QOL compared with the patients in the control group.

The shift from inpatient to outpatient cancer treatment has increased awareness of patients' selfcare strategies and also of their significant others including family members and close friends (Klafke et al., 2014). Cancer has become a family disease affecting not only the individual with the cancer diagnosis, but also involving their significant others who often are experiencing high levels of distress while accompanying and supporting their loved one going through the treatment stages and adjusting to a new life situation .

A strength of the current study is the consideration of patients' significant others, the interventions have been primarily composed for the patient receiving chemotherapy, and significant others who implemented the interventions. Thus, the current study contributed to bonding and improvements of QOL in cancer patients' significant others. To our knowledge, this is one of the first nurse-led intervention studies in Egypt that can assess nurses' relevant contribution in promoting QOL during cancer therapy.

Regarding the relationship between the studied women QOL, socio-demographic data, social stressors, and clinical characteristics there is no significant correlation between socio-demographic data and QOL as regards study and control groups of the studied women except on the control group; income was a significant predictor of positive effect on QOL during the first visit $(\mathrm{r}=0.344, \mathrm{p}<0.05)$, and stage at diagnosis was a significant predictor of negative effect on QOL during the first visit ( $r=-$ $0.523, \mathrm{p}<0.05)$. These findings are in line with Wilailak et al., (2011) in Thailand regarding association with financial status who studied QOL in gynecological cancer survivors compared to healthy check-up women and found the QOL scores were higher in gynecological cancer patients after treatment. And the factors that associated with the higher score in the patient group are having husband as a caregiver, no financial problem, eastern cooperative oncology group score 0 or 1 and having high school or higher education.

Moreover, it contradict with Awadalla et al., (2007) in Kuwait who studied factors associated with QOL of outpatients with breast cancer and gynecological cancer and their family caregivers and found that education was the only caregiver characteristic that had a significant association with patient's QOL. And Loizzo et al., (2010) confirmed that patients who were married, with higher education, better employment, and with longer duration of illness had higher QOL. Patients on radiotherapy and their caregivers had higher QOL scores. They found that younger patients had poorer QOL which might have resulted from unexpectedness of impaired fertility and femininity, treatment-related menopause and relationship issues.

Findings of the current study reflected that advanced stage of disease led to deterioration of general condition. On the other hand, in the study group, receiving chemotherapy was a significant predictor of positive effect on QOL after implementation of the program $(r=0.294, p<0.05)$. In accordance, as the great majority of the study group received chemotherapy, this implies that intervention worked so well in improving QOL as they engaged and followed the women over time teaching them to manage their physical and mental health problems concurrently associated with chemotherapy.

The findings of the present study revealed that the educational program succeed in improvement of psychological status and consequently in the cancer patient QOL.

\section{Conclusion}

The current study showed that the women who received nursing intervention program showed evidence of improved QOL, with a reduction in the sexual dysfunction incidence, and lower stress levels. There is no significant difference between reproductive concerns and QOL in the study and control group $(\mathrm{p}>0.05)$. All of the study group women who had poor QOL had severe stress in the first visit $(\mathrm{P}>0.05)$, while in the last visit two thirds of women who had good QOL had mild stress ( $P>0.05)$. The findings from the present study add to the growing body of evidence that nurseadministered educational interventions are effective in helping patients manage physical and psychological symptom related to cancer treatment that negatively affect women QOL. 


\section{Recommendations}

Based upon findings of the current study, it is suggested to give health education program to heighten awareness and knowledge about the treatment-related side effects among the nursing staff. More studies are needed to investigate longerterm effect of such programs and plan individualized education program emphasizing on unique needs of each patient.

\section{References}

1. American Cancer Society. (2012): Retrieved from

http://www.cancer.org/research/cancerfactsstati stics/allcancerfactsfigures/index

2. American Cancer Society. (2013): Cancer Facts and Figures, 2013. Atlanta, GA: American Cancer Society.

3. Anderson D., Seib C., mccarthy A., Yates P., Porter-Steele J., meguire A., (2015): Facilitating lifestyle changes to manage menopausal symptoms in women with breast cancer: a randomized controlled pilot trial of The Pink Women's Wellness Program. Menopause..

4. Asukai, N., |\& Kato, H., (2002): Reliability and validity of the Japanese-language version of the Impact of event scale-revised (IES-R-J). Journal of Nervous and Mental Disease. 190 (3): 175-182.

5. Awadalla A., Ohaeri J., Gholoum A., Khalid A., Hamad H., \& Jacob A., (2007): Factors associated with quality of life of outpatients with breast cancer and gynecologic cancers and their family caregivers: a controlled study. BMC Cancer.: ;7. 102.

6. Aziz, N., (2007): Cancer survivorship research: State of Knowledge, challenges and opportunities. ActaOncologica, 46, 417-432.

7. Badr H., Krebs P., (2013): A systematic review and meta-analysis of psychosocial interventions for couples coping with cancer. Psychooncology.;22:1688-1704.

8. Brotto L., Heiman J., Goff B., Greer B., Lentz G., |\&Swisher E., (2008): A psychoeducational intervention for sexual dysfunction in women with gynecologic cancer. Arch Sex Behav.; 37: 317-29.

9. Cella, D., (1997): Functional Assessment of Chronic Illness Therapy (FACIT) measurement system manual version 4. Center on Outcomes, Research and Education (CORE). Evanston Northwestern Healthcare and Northwestern University: IL.

10. Collins A., Love A., Bloch S., Street A., Duchesne G., Dunai J., Couper J., (2013):
Cognitive existential couple therapy for newly diagnosed prostate cancer patients and their partners: a descriptive pilot study. Psychooncology.;22:465-469.

11. Creamer, M., Bell, R., \&Falilla, S., (2002): Psychometric properties of the Impact of Event Scale-Revised. Behaviour Research and Therapy. 41: 1489-1496.

12. Fahimeh Sehati Shafaee, F.,Mirghafourvand, M., Harischi, S., Esfahani, A., \& Amirzehni, (2018): SelfConfidence and Quality of Life in Women Undergoing Treatment for Breast Cancer Asian Pac J Cancer Prev. 2018; 19(3): 733-740.

13. Faller H., Schuler M., Richard M., Heckl U., Weis J., \&Küffner R., (2013): Effects of psycho-oncologic interventions on emotional distress and quality of life in adult patients with cancer: systematic review and meta-analysis. $\mathbf{J}$ ClinOncol. 20; 31(6):782-93.

14. Ganz P., Kwan L., Stanton A., Bower J., \& Belin T., (2011): Physical and psychosocial recovery in the year after primary treatment of breast cancer. J ClinOncol.; 29: 1101.

15. Goel, S., Sharma, R., Hamilton, A., \&Beith, J., (2009): LHRH agonists for adjuvant therapy of early breast cancer in premenopausal women. Cochrane Database Syst Review, 4, 140.

16. Ibrahim, Hussein M., Khaled, Nabiel N., Mikhail, Hoda Baraka, \& Hossam Kamel (2014): Cancer Incidence in Egypt: Results of the National Population-Based Cancer Registry Program. Journal of Cancer Epidemiology Volume 2014 (2014), Article ID 437971, 18 pages.

17. Jeffries S., Robinson J., Craighead P., \&Keats M.. (2006): An effective group psychoeducational intervention for improving compliance with vaginal dilation: A randomized controlled trial. Int $\mathbf{J}$ RadiatOncolBiol Phys.;65:404-11.

18. Jones G., Ledger W., \&Bonnett T., (2006): The impact of treatment for gynecological cancer on health-related quality of life (HRQOL): a systematic review. Am J ObstetGynecol; 194:26-42.

19. Kawamura, N., Yoshiharu, K., \& Nozomu, A., (2001): Suppression of Cellular Immunity in Men with a Past History of Post-Traumatic Stress Disorder. American Journal of Psychiatry. 158: 484-486

20. Klafke N., Eliott J., Olver I., \&Wittert G., (2014): The varied contribution of significant others to Complementary and Alternative Medicine (CAM) uptake by men with cancer: 
A qualitative analysis. Eur J OncolNurs.; 18(3):329-36.

21. Klafke, N., Mahler, C., Von Hagens, C., Rochon, J., Schneeweiss, A., Andreas Müller, A., Salize, H., \& Joos S., (2015): A complex nursing intervention of complementary and alternative medicine (CAM) to increase quality of life in patients with breast and gynecologic cancer undergoing chemotherapy: study protocol for a partially randomized patient preference trial

22. Lau, A., Chang, C., Tai, J., Eremenco, S., Liang, R., Lie, A., \&Lau, C., (2002): Translation and validation of the Functional Assessment of Cancer Therapy-Bone Marrow Transplant (FACT-BMT) version 4 quality of life instrument into traditional Chinese. Bone Marrow Transplant, 29, 41-49.

23. Liao M., Chen S., Lin Y., Chen M., Wang C., Jane S., (2014): Education and psychological support meet the supportive care needs of Taiwanese women three months after surgery for newly diagnosed breast cancer: A non-randomised quasi-experimental study. Int $\mathbf{J}$ Nurs Stud. ;51:390-9.

24. Loh S., Packer T., Chinna K., \&Quek K., (2013): Effectiveness of a patient selfmanagement programme for breast cancer as a chronic illness: a non-randomised controlled clinical trial. J Cancer Surviv. 2013 Sep;7(3):331-42. Doi: 10.1007/s11764-0130274-x. Epub Mar 22.

25. Loizzo, Joseph J., Peterson, Janey C., Charlson, Mary E, Wolf, Emily J, Altemus, \& Margaret, (2010): the effect of a contemplative self-healing program on quality of life in women with breast and gynecologic cancers alternative therapies in health and medicine; Aliso Viejo 16.3 (May/Jun): 30-7.

26. Marmar, C., Weiss, D., Metzler, T., Ronfeldt, H., \& Foreman, C., \& (1996): Stress responses of emergency services personnel to the Loma Prieta earthquake Interstate 880 freeway collapse and control traumatic incidents. Journal of Traumatic Stress, 9(1), 63-85.

27. Miaskowski, C., Dodd, M., West, C., Schumacher, K., Paul, S., \& Tripathy, D., (2004): Randomized clinical trial of the effectiveness of a self-care intervention to improve cancer pain management. Journal of Clinical Oncology, 22, 1713-1720.

28. Milne H., Wallman K., Gordon S., \& Courneya K., (2008): Effects of a combined aerobic and resistance exercise program in breast cancer survivors: A randomized controlled trial. Breast Cancer Res Treat.;108:279-88.

29. National Cancer Institute Dictionary. (2010): Gynecologic cancer. Retrieved from http://www.cancer.gov/dictionary/?Cdrid=4598 2.

30. Powell C., Kneier A., Chen L., Rubin M., Kronewetter C., |\&Levine E., (2008): randomized study of the effectiveness of a brief psychosocial intervention for women attending a gynecologic cancer clinic. Gynecol Oncol.;111:137-43.

31. Regino, P., Elias. C., Pereira \&Pissetti, C., (2017): Quality of Life of Patients with Breast and Gynecological Cancer Faced with Anticancer Chemotherapy Vol. 10 No. 233

32. Rosen, R., Brown, C., Heiman, J., Leiblum, S., Meston, C., Shabsigh, R., \& D'Agostino, R., (2000): The Female Sexual Function Index (FSFI): a multidimensional self-report instrument for the assessment of female sexual function. Journal of Sexual and Marital Therapy, 26(2), 191-208.

33. Rosen, R., Brown, C., Heiman, J., Leiblum, S., Meston, C., Shabsigh, R., D'Agostino R., (2000): The Female Sexual Function Index (FSFI): a multidimensional self-report instrument for the assessment of female sexual function. Journal of Sexual and Marital Therapy, 26(2), 191-208.

34. Ruddy, K., Gelber, S., Tamimi, R., Ginsburg, E., \& Lidia Schapira, (2014): Prospective Study of Fertility Concerns and Preservation Strategies in Young Women with Breast Cancer, Journal of Clinical Oncology.

35. Ruth McCorkle1, Michael Dowd, lizabeth Ercolano, Dena Schulman-Green, Anna-leila Williams, Mary Lou, Siefert, Jeanne Steiner, \& Peter Schwartz, (2009): Effects of a nursing intervention on quality of life outcomes in post-surgical women with gynecological cancers.

36. Shahsavari, H., Matory, P., Zare, Z., Fariba Taleghani, \& Akbari Kaji3 M., Educ Health Promot (2015): Effect of self-care education on the quality of life in patients with breast cancer.

37. Shapinsky, A., Rapport, L., Henderson, M., \& Axelrod, B., (2005): Civilian PTSD scales: relationships with trait characteristics and everyday distress. Assessment, 12(2), 220-230.

38. Speck, C., Gross, J., \& Hormes, B., (2010): "Changes in the body image and relationship scale following a one-year strength training trial for breast cancer survivors with or at risk for lymphedema," Breast Cancer Research and 
Treatment, vol. 121, no. 2, pp. 421-430,. View at Publisher . View at Google Scholar.

39. Weaver K., Forsythe L., Reeve B., (2012): Mental and physical health-related quality of life among U.S. cancer survivors: population estimates Cancer Epidemiol Bio-markers Prev.; 21: 2108-2117.

40. Wenzel, L., dealba, I., Habbal, R., Kluhsman, B., Fairclough, D., Krebs, L., U., \& Aziz, N., (2005): Quality of life in longterm cervical cancer survivors. Gynecologic Oncology, 97(2), 310-317.

41. Wiegel M., Meston C., Rosen R., (2005): The female sexual function index (FSFI): crossvalidation and development of clinical cutoff scores. J Sex Marital Therapy; 31: 1-20.

42. Wilailak, S., Lertkhachonsuk, A., Lohacharoenvanich,N., Luengsukcharoen, S., Jirajaras, M., Likitanasombat, P., \&Sirilerttrakul, S., (2011): Quality of life in gynecologic cancer survivors compared to healthy check-up women J GynecolOncol. Jun 30; 22(2): 103-109.

43. World Health Organization (2014): Cancer Country Profiles, Egypt (2014). 